\title{
ambient SCIENCE

\section{A Survey on Acquired Knowledge of the Medical Students to Handle Illegal Abortion Cases: a Case Study of Iran}

\section{Seyedsaeid Seyedian', Sekineh Barfar², Sasan Mogahi ${ }^{3}$, Maria Cheraghi, ${ }^{4,5}$ Alireza Nabipour ${ }^{6}$, Amirreza Dadgarinejad ${ }^{4}$, Farkhondeh Jamshidi ${ }^{34 *}$}

'Alimentary Tract Research Center, Ahvaz Jundishapur University of Medical Sciences, Ahvaz, Iran

${ }^{2}$ Student Research Committee, Ahvaz Jundishapur University of Medical Sciences, Ahvaz, Iran

${ }^{3}$ School of Medicine, Ahvaz Jundishapur University of Medical Sciences, Ahvaz, Iran

${ }^{4}$ Social Determinant of Health Research Center, Ahvaz Jundishapur University of Medical Sciences, Ahvaz, Iran

${ }^{5}$ Department of Public Health, School of Health, Ahvaz Jundishapur University of Medical Sciences, Ahvaz, Iran

${ }^{6}$ Poona College of Pharmacy, University of Bharati Vidyapeeth, Pune, India

Study Area: Ahvaz, Iran

Coordinates: $31^{\circ} 19^{\prime} 13^{\prime \prime} \mathrm{N}$; $48^{\circ} 40^{\prime} 09^{\prime \prime E}$

Key words: Pregnancy Complications, Pregnancy Awareness, Unsafe abortion, Unwanted Pregnancy

This study was conducted after gaining permission from the Scientific Ethics Committee of Jundishapur University of Ahvaz (Ethics Code: IR.AJUMS.REC.1396.1037).

\section{Introduction:}

In the present scenario, total Twenty two million unsafe abortions are done annually in the world, out of which an estimated death of 47,00o women and disabilities for an additional 5 million women (Ahman \& Shah, 2011). Unsafe abortion accounts for $13 \%$ of all pregnancy-related deaths in women which leads to 67,00o maternal deaths and 5 million permanent or temporary disabilities per year (Fallahian \& Mohammad-Zadeh, 2005; Glasier et al., 2006) in Iran and some other countries. About $98 \%$ of unsafe abortions take place in developing countries (WHO, 2013). There are no exact statistics on illegal abortions, mortality rates, and illnesses from Iran yet. However, according to an estimate, 80,00o illegal abortions are conducted in Iran per year (Chinichian et al., 2008; Shamshiri-Milani, 2005). Illegal abortions are continual issues in all parts of Iran and among different classes of people with different levels of cultural and literacy which is carried out in society for

\section{Abstract}

Unsafe abortion, which is defined as the termination of an unwanted pregnancy by a person lacking the necessary skills or in an environment lacking minimal medical standards, could cause a high percentage of pregnancy-related deaths. Since day by days numbers of unsafe abortions in developing countries are increasing, this study planned to know the awareness among 240 medical students about illegal abortion by conducting a descriptive study. Volunteer students were randomly selected, then a questionnaire containing demographic information (age, sex, educational level, marital status) and 12 questions related to awareness on illegal abortion were distributed among them to provide personal responses of the questions. Finaly, the score of 11 and above was given to the appropriate knowledge. Total $82.7 \%$ of the students were scored over 11 revealed a good knowledge regarding the illegal abortion in the country. Also, $55 \%$ of students recommended for considering the abortion as illegal to prevent complications caused by illegal abortions. Our results indicated that there were a good awareness and adequate knowledge among students of medicine about illegal abortion and its complications.

various reasons (Chinichian et al., 2005). In preventing illegal abortion, suppressive laws and policies were largely ineffective (Shamshiri-Milani, 2005). There were not any appropriate solutions to prevent intentional abortions (Khalaj-Abadi-Faraahani \& Sadat-Hashemi, 2002). The results of a study over 62 householder women under the coverage of rural health house showed that $32 \%$ of women having unwanted pregnancy had taken unsuccessful action or attempts to terminate their pregnancy, which was done by various physical methods, use of non-medical vaginal tools, injection methods, food or combinations of multidrugs (Alaviche et al., 2004).

Now the time came to pay attention to the issue of illegal abortion and to find suitable educational solutions based on a community of participants and families, such as the implementation of successful family planning and contraceptive methods. Since most women who perform abortions, have spouses and children (Shamshiri-Milani, 
2005) and due to unwanted pregnancies resort to this deed. Thus, the promotion of women's awareness, especially at the time of marriage can be the basis of preventive measures. This study was carried out to determine the awareness of illegal abortion among medical students as one of the main elements of counseling services to people and a way to inform them about the dangers of unsafe abortion.

\section{Methodology:}

This is a descriptive study conducted on medical students of Ahwaz University of Medical Sciences in the early part of the year 2018. Among the volunteer students, 240 students aged in between 18 to 29 years were randomly selected. A questionnaire containing demographic information (age, sex, educational level, marital status) and 12 questions related to awareness on illegal abortion were distributed among the participants who personally responded to the questions. The answers were qualitatively defined including, 'Yes=2', 'I do not know=1' and 'No=o, finally, after collecting the scores of each questionnaire, the score of 11 and higher was considered as suitable knowledge.

\section{Results:}

The demographic and educational information of the 240 medical students participating in the study is shown in Table-1.

Table-1: Demographic and educational data of medical students participating in the study

\begin{tabular}{|c|c|c|}
\hline \multicolumn{2}{|l|}{ Variables } & $\mathrm{N}(\%) /$ Mean \pm SD \\
\hline \multicolumn{2}{|c|}{ Age (year) } & $25.26 \pm 1.95$ \\
\hline \multirow[t]{2}{*}{ Gender } & Female & $144(60 \%)$ \\
\hline & Male & $96(40 \%)$ \\
\hline \multirow[t]{2}{*}{ Marital Status } & Single & $171(71.3 \%)$ \\
\hline & Married & $69(28.8 \%)$ \\
\hline \multirow[t]{4}{*}{ Grade } & Basic & $47(19.5 \%)$ \\
\hline & Physiopath & $40(16.7 \%)$ \\
\hline & Extern & $24(10 \%)$ \\
\hline & Intern & $129(53.8 \%)$ \\
\hline
\end{tabular}

Students' awareness of illegal abortion was measured by 12 questions. The students' performance on these questions is shown in Table-2.

In the end, after calculating the scores of the questionnaires, $82.7 \%$ of the students earned a score - 11 , indicating proper knowledge of the conditions of abortion in the country.

Among the people who had good knowledge about this subject, the highest percent of questions ( $41.7 \%$ ) belonged to the students who have introduced the teachers as their educational source. After that, the second highest percentage (15.3\%) belonged to students who had come to the knowledge through appropriate study. Other ways of acquiring information were through friends (11.1\%), television (15.3\%) and conferences (2.4\%).
Table-2: Responses to the questions based on the number of items selected by the students

\begin{tabular}{llll}
\hline Questions & YES & Don't Know & NO \\
& $\mathrm{N}(\%)$ & $\mathrm{N}(\%)$ & $\mathrm{N}(\%)$ \\
\hline Existence of illegal abortions & 87 & & 153 \\
among friends and relatives & $(36.3 \%)$ & $(63.8 \%)$ \\
- Familiarity with the meaning & 216 & & 24 \\
of illegal abortion & $(90 \%)$ & $(10 \%)$ \\
- Free talk about illicit abortion & 179 & & 61 \\
in school and university & $(74.6 \%)$ & & $(25.4 \%)$ \\
- Probability of illness after & 48 & 78 & 114 \\
abortion & $(20 \%)$ & $(32.5 \%)$ & $(47.5 \%)$ \\
- Probable serious risks of & 195 & 24 & 21 \\
illegal abortion & $(81.3 \%)$ & $(10 \%)$ & $(8.7 \%)$ \\
- Knowing the Persons doing & 33 & & 207 \\
Illegal Abortions & $(13.8 \%)$ & - & $(86.2 \%)$ \\
Desire to have child & $96(40 \%)$ & $144(60 \%)$ \\
- Awareness about abortion & 18 & 12 & 180 \\
laws of Iran & $(7.5 \%)$ & $(5 \%)$ & $(75 \%)$ \\
- Suggesting to have free & 132 & & 108 \\
abortion right in Iran & $(55 \%)$ & & $(45 \%)$ \\
- Recommending abortion in & 30 & 93 & 117 \\
the case of unwanted & $(12.5 \%)$ & $(38.7 \%)$ & $(48.8 \%)$ \\
pregnancy in your relatives & & & \\
-Thinking about abortion for & 36 & 78 & 156 \\
applicants & $(15 \%)$ & $(20 \%)$ & $(65 \%)$ \\
- Personal history of abortion & 0 & - & 240 \\
& & & $(100 \%)$ \\
\hline
\end{tabular}

\section{Discussion:}

One of the major threats to the health and welfare of women throughout the world is intentional abortion, especially, the unhealthy abortions due to unwanted pregnancies. Education and awareness, despite providing ground for preventing abortion, are essential parts of reducing the complications of unhealthy abortions. Hence, family planning organizations, on the one hand, will provide comprehensive contraceptive care services to prevent unwanted pregnancies, and on the other hand, in case of failure of methods and facing unwanted pregnancies, they provide safe and healthy abortion services (Fallahian \& Mohammad-Zadeh, 2005; Shamshiri-Milani, 2005; KhalajAbadi-Faraahani \& Sadat-Hashemi , 2002; Alaviche et al., 2004; Erfani, 2008). Accordingly, education and prevention of unwanted pregnancies should always be considered in advance against any attempted abortion. In many cases, contrary to common belief, women who resort to abortion are often married, have stable lives and several children who failed in controlling their pregnancy, do not have access to modern prevention methods, financial inadequacy or other reasons. Few changes in legislation and legal policies in Romania were successful in reducing the mortality rate up to more than 5.2 times (McFarlane, 1993). The Netherlands also achieved the lowest abortion rate by providing affordable access to contraceptive methods and free abortion services for the society (Ardakani et al., 2005). In a study in Kerman, Ghadipasha et al. (2008) evaluated 143 
obstetricians and gynecologists in terms of their awareness of abortion and regulations laws where $14 \%$ of subjects were the gynecologist and $86 \%$ were midwives, $15.4 \%$ had a moderate knowledge and $84.6 \%$ had good knowledge. There was a significant relationship evidenced between education and job status and knowledge level. Høvik \& Hestvik (2014) compared the awareness of recent medical students about abortion with the knowledge of newcomers where $90 \%$ of the Senioritis consider abortion legal under certain circumstances illegal, and $4.2 \%$ believed that abortion was illegal under any conditions. Most of the first year students were opposed to abortion and disagreed with Senioritis.

Therefore, it seems that legislation should change the legal policies and use the concept of health from the perspective of the World Health Organization that emphasizes on psychosocial well-being, exclude the abortion laws from the crime list and contribute to declining in the percentage of illnesses and mortality due to unhealthy abortions. In future studies, through an extensive study among women who have been unwontedly pregnant can be studied the prevalence of abortion and its possible complications.

Conclusively, the results of this study indicated a good awareness of illegal abortion among students of medicine and they had enough knowledge about the complications of abortion. They also suggested that people should have the freedom to make abortion in order to prevent complications caused by illegal abortions.

\section{Acknowledgment:}

The study was financially supported by Ahvaz Jundishapur University of Medical Sciences (Grant No.: GP95116).

\section{References:}

Ahman, E. \& Shah, I.H. (2011): New estimates and trends regarding unsafe abortion mortality.Int. J.Gynaecol. Obstet., 115(2):121-126.
Ardakani, Z.B., Akhondi, M.M., Sadeghi, M.R., Sadri-Ardakani, H. (2005): Necessity of examining the different dimensions of abortion in Iran. J. Repro. Infert., 6(4):229-320.

Chinichian, M., Holakouie Naieni, K. \& Refaee Shirpak, Kh. (2008): Reasons of induced abortion in Iran, a qualitative study. Payesh, 6(3):219-223.

Erfani, A. (2008): Abortion in Iran: What do we know? $\underline{\text { PSC Disc. }}$ Papers Ser., 22(1):\#1.

Fallahian, M. \& Mohammad-Zadeh, F.(2005): Trends in abortion in Iran:1994-2002. Arch. Iranian Med., 8 (3):217-218.

Ghadipasha, M., Gharahdaghi, J., Hejazi Aria, Aminian, Z., Shams Mldini Motlagh, F., Zarenezhad M. (2009): The study of knowledge of gynecologists and midwives in kerman concerning the abortion rules and regulationis in 2008 . Iranian J. Forensic Med.,15(3):176-181.

Glasier, A., Gülmezoglu, A.M., Schmid, G.P., Moreno, C.G., Van Look, P.F. (2006): Sexual and reproductive health: a matter of life and death. Lancet, 368(9547):1595-1607.

Høvik H. \& Hestvik, L.K. (2014): Knowledge and attitudes towards abortion among medical students at the University of Buenos Aires, Argentina (Medical student research project 2012/2014).

Khalaj-Abadi-Farahani, F. \& SadatHashemi, S.M. (2002): Factors influencing unwanted pregnancies in Tehran. Hakim Res. J., 5:201-206.

McFarlane, D.R. (1993): Induced abortion: an historical overview. Am. J. Gynecol. Health, 7(3):77-82.

Shamshiri-Milani, H. (2005): Mother's rights to life, a medical approach to abortion. L. Repro. Infert., 6(4):457-464.

Zamani Alaviche F, Eftekhar Ardebili H, Bashardost N, Marashi T, Naghibi A. The behavior of women confronted with unwanted pregnancies. J. School Pub. Health Inst. Pub Health Res., 2(2):55-62. 